\title{
Rainfall Enhancement Due to Scavenging of Cooling Tower Condensate
}

by

M. T. Dana

M. A. Wolf

September 1977

Prepared for the Energy Research and Development Administration under Contract EY-76-C-06-1830 
NOTICE

This report was prepared as an account of work sponsored by the United States Government. Neither the United States nor the Energy Research and Development Administration, nor any of their employees, nor any of their contractors, subcontractors, or their employees, makes any warranty, express or implied, or assumes any legal liabil ty or responsibility for the accuracy, completeness or usefulness of any information, apparatus, preduct or process disclosed, or represents that its use would not infringe privateiy owned rights.

The views, opinions and conclusions contained in this report are these of the contractor and do not necessarily represent those of the United States Government or the United States Energy Research and Development Administration.

\author{
PACIFIC NORTHWEST LABORATORY \\ operated by \\ BATTELLE \\ for the \\ ENERCY RESEARCH AND DEVELOPMENT ADMINISTRATION \\ Under Contract EY-76-C-06-1830
}

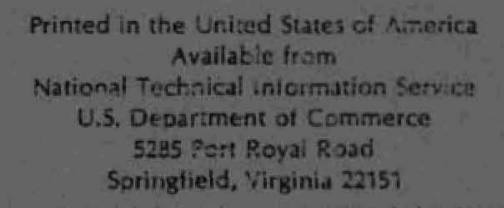

Price: Printed Copy

$\therefore$ Micrafiche $\$ 3.00$

$\begin{array}{cc}\text { sPages } & \text { NTIS } \\ \text { Selling Price } \\ 001-025 & \$ 4.50 \\ 026-050 & \$ 5.00 \\ 051-0175 & \$ 5.50 \\ 076-100 & \$ 5.00 \\ 101-125 & \$ 5.50 \\ 126-150 & 57.00 \\ 151-175 & \$ 7.75 \\ 176-200 & \$ 3.50 \\ 201--2.25 & \$ 8.75 \\ 225-250 & \$ 9.00 \\ 237-275 & \$ 10.00 \\ 276-300 & \$ 10.25\end{array}$


BNWL-2295

UC -12

RAINFALL ENHANCEMENT DUE TO SCAVENGING

OF COOLING TOWER CONDENSATE

by

M. T. Dana

M. A. Wolf

Sep tember 1977

Battelle

Pacific Northwest Laboratories

Richland, Washington 99352 



\section{ABSTRACT}

Estimates of rainfall enhancement resulting from scavenging of c00ling tower condensate droplets were made using relevant aerosol scavenging theory and a range of meteorological conditions. For a large natural-draft tower, releasing $1.7 \times 10^{5} \mathrm{~g} / \mathrm{sec}$ of condensate, plume centerline rainfa 1 enhancement is predicted to be measurably high at downwind distances between $100 \mathrm{~m}$ and $1 \mathrm{~km}$ for moderate wind speeds and rainfall rates. The cumulative removal of condensate by scavenging should be significant, even in a light rain $(1 \mathrm{~mm} / \mathrm{hr})$, where removal "half-distances" are predicted to be 2.5 , 10 , and $20 \mathrm{~km}$ for wind speeds of 1,5 , and $10 \mathrm{~m} / \mathrm{sec}$, respectively. 
•

。 


\section{CONTENTS}

ABSTRACT . . . . . . . . . . . . . . . . . . . . . .

FIGURES. . . . . . . . . . . . . . . . . . . . . iv

TABLES . . . . . . . . . . . . . . . . . . . . v v

NOMENCLATURE . . . . . . . . . . . . . . . . . . . . . . . . . vi

INTRODUCTION . . . . . . . . . . . . . . . . . . . . . . 1

AEROSOL SCAVENGING THEORY. . . . . . . . . . . . . . . . . . 2

CALCULATION OF RAINFALL ENHANCEMENT. . . . . . . . . . . . . . 4

SAMPLE CALCULATIONS. . . . . . . . . . . . . . . . . . 10

CONCLUSIONS AND RECOMMENDATIONS. . . . . . . . . . . . . . . 25

REFERENCES . . . . . . . . . . . . . . . . . . 28

APPENDICES

I. Determination of Apparent Condensate Flow Rate

from a Typical, Large Natural Draft Cooling Tower . . . . 29

II. Plume Droplet Size Distribution Used in

Scavenging Estimates. . . . . . . . . . . . 32 


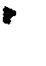

.

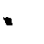

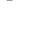




\section{FIGURES}

1 Schematic of Plume and Raindrop Trajectory Geometry . . . . . 7

2 Rainfall Enhancement (Concentration of Scavenged Condensate) at the Plume Centerline vs. True Downwind

Distance: Cases of $u=1 \mathrm{~m} / \mathrm{sec}$ and $\mathrm{J}=1$ and $5 \mathrm{~mm} / \mathrm{hr} \ldots 13$

3 Rainfall Enhancement (Concentration of Scavenged

Condensate) at the Plume Centerline vs. True Downwind

Distance: $u=5 \mathrm{~m} / \mathrm{sec}$............... 14

4 Rainfall Enhancement (Concentration of Scavenged

Condensate) at the Plume Centerline vs. True Downwind

Distance: $u=10 \mathrm{~m} / \mathrm{sec}$............. 15

5 Cross-plume Average Rainfall Enhancement: Cases of

$u=1 \mathrm{~m} / \mathrm{sec}$ and $\mathrm{J}=1$ and $5 \mathrm{~mm} / \mathrm{hr} \ldots \ldots 17$

6 Cross-plume Average Rainfall Enhancement: $u=5 \mathrm{~m} / \mathrm{sec} \ldots . .18$

7 Cross-plume Average Rainfall Enhancement: $u=10 \mathrm{~m} / \mathrm{sec} \ldots 19$

8 Examples of Cross-plume Rainfall Enhancement Patterns When

Calculation is Done Using Either Slanted Raindrop or

Vertical Raindrop Trajectories. ............ 20

9 Cumulative Removal of Condensate by Scavenging: Cases

of $u=1 \mathrm{~m} / \mathrm{sec}$ and $\mathrm{J}=1$ and $5 \mathrm{~mm} / \mathrm{hr}$.......... 22

10 Cumulative Removal of Condensate by Scavenging:

$u=5 \mathrm{~m} / \mathrm{sec} \ldots \ldots \ldots . \ldots 23$

11 Cumulative Removal of Condensate by Scavenging:

$u=10 \mathrm{~m} / \mathrm{sec} \ldots \ldots \ldots . \ldots 24$ 


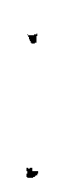




\section{TABLES}

1 Input Parameters Used in Calculations of Rainfall

Enhancement .................... 11

2 Discrete Raindrop Spectrum Used in Calculations

of Rainfall Enhancement ............... . 11

3 Plume Parameters Derived From Input Data of

Table 1, and Geometry of Figure 1. . . . . . . . . . . 12

4 Conditions for Example Condensed Water Calculation. . . . . . 29

5 Condensed Water Calculations for Example Cooling

Tower Plume . . . . . . . . . . . . . . . . . 30

$6 \quad$ Plume Droplet Spectrum Used in Scavenging Estimates

Measured at Trojan Power Plant on May 13, 1976. . . . . . . 33 
.

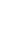




\section{NOMENCLATURE}

Units: 1, length; t, time; m, mass; none, dimensionless; $e$, energy; $T$, temperature

Symbol

A

a

C

$\mathrm{CW}$

E

EN

$\mathrm{F}$

$f$

H

$H^{\prime}$

h

i

J

k

LWC

MR

$\operatorname{mix}$

n

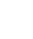

Units

1

$\mathrm{m} / 1^{3}$

$\mathrm{m} / \mathrm{m}$

$e / m$

$1^{-2} t^{-1}$

1

1

1

$1 / t$, or $m / 1^{2} t$

$t^{-1}$

$m / 1^{3}$

$\mathrm{m} / \mathrm{m}$ 



\begin{tabular}{|c|c|c|}
\hline Symbol & Units & Definition \\
\hline $\mathrm{p}$ & 1 & Dimension of path of raindrop \\
\hline Q & $\mathrm{m} / \mathrm{t}$ & Source term for condensate \\
\hline$Q_{0}$ & $\mathrm{~m} / \mathrm{t}$ & Source term for condensate at time $t=0$ \\
\hline$R$ & 1 & Raindrop radius \\
\hline$S$ & & Stokes parameter \\
\hline$T_{w}$ & $T$ & Wet-bulb temperature \\
\hline$t$ & $\mathrm{t}$ & Time \\
\hline u & $1 / t$ & Wind velocity \\
\hline$v_{1}$ & $1 / t$ & Average loft velocity of plume \\
\hline$v_{t}$ & $1 / t$ & Terminal velocity of raindrop \\
\hline W & 1 & Diameter of cooling tower mouth \\
\hline$x$ & 1 & Dimension downwind from virtual source \\
\hline$x^{\prime}$ & 1 & $\begin{array}{l}\text { Distance downwind where raindrop crosses } \\
\text { plume centerline }\end{array}$ \\
\hline$x_{L}$ & 1 & Distance downwind where plume levels off \\
\hline$x_{r}$ & 1 & $\begin{array}{l}\text { Distance of real source downwind of } \\
\text { virtual source }\end{array}$ \\
\hline Y & 1 & $\begin{array}{l}\text { Total width of plume or deposition } \\
\text { pattern }\end{array}$ \\
\hline$y$ & 1 & Cross-plume dimension \\
\hline$z$ & 1 & Vertical dimension \\
\hline$\Delta H$ & 1 & $\begin{array}{l}\text { Height of leveled-off plume above } \\
\text { real source height }\end{array}$ \\
\hline$v$ & $1^{2} / t$ & Kinematic viscosity of air \\
\hline$P_{a}$ & $\mathrm{~m} / 1^{3}$ & Mass density of air \\
\hline$P_{W}$ & $\mathrm{~m} / \mathrm{1}^{3}$ & $\begin{array}{l}\text { Mass density of condensate droplets } \\
\text { (water) }\end{array}$ \\
\hline
\end{tabular}


Symbol

$$
\sigma_{y}, \sigma_{z}
$$

$x$

$x_{v}$

$x_{W}$
Units

1

$\mathrm{m} / 1^{3}$

$\mathrm{m} / 1^{2}$

$\mathrm{m} / 1^{2}$
Definition

Standard deviation of plume spread in $y$ and $z$ directions

Air concentration of plume droplets

Vertical integral (z-direction) of $x$

Integral of $x$ in $p$-direction (along raindrop path) 
I 
RAINFALL ENHANCEMENT DUE TO SCAVENGING

OF COOLING TOWER CONDENSATE

\section{INTRODUCTION}

The recent increase in the number of electrical generating plants which use cooling towers and projections for further expansion have prompted considerable concern about the environmental impact of large releases of energy and water effluent. One aspect of a comprehensive research program, Meteorological Effects of Thermal Energy Releases (METER), sponsored by the Energy Research and Development Administration, is an examination of the physical effects of the vast amounts of water vapor and condensate (tens of thousands of $\mathrm{kg}$ per second) regularly released by modern cooling towers. Such large releases can significantly affect water vapor and cloud-related natural processes at least in the immediate vicinity. One question concerns the effect on natural precipitation; namely, the potential for significant enhancement of precipitation rates and amounts in the sector traversed by the condensate plume.

In this report, we consider theoretically the question of precipitation scavenging of condensate droplets by natural precipitation, and the resultant enhancement of precipitation under the plume. Scavenging of the vapor component of the effluent is not considered here, nor are scavenging processes occurring purely as a result of cloud droplet-water vapor interactions (nucleation, droplet growth by accretion, etc.), which are commonly referred to as "in-cloud" scavenging processes, or "rain out." We consider the interaction between raindrops and condensate cloud droplets, generally called "below-cloud" scavinging or "washout" (although, of course, these interactions do occur within clouds as well as outside them). The approach is to use the currently accepted below-cloud scavenging theory to estimate for somewhat ideal cases the degree of potential rainfall enhancement; comments regarding the efficacy of this approach and recommendations for experimental evaluations and other calculations appear in the concluding section. 
- 


\section{AEROSOL SCAVENGING THEORY}

In treating the removal of water droplets from a plume by rainfall, we will use the traditional concept of a scavenging ("washout") coefficient, or fraction of the emitted liquid water which is removed per unit time. This removal may be expressed as an exponential decay process

$$
Q(t)=Q_{0} \exp (-k t),
$$

where $Q_{0}$ and $Q(t)$ are the source terms (mass/time) at times $t=0$ and $t$, respectively. The theoretical derivation of $k$ for the removal of aerosol particles by raindrops is treated in detail elsewhere; ${ }^{1}$ for present purposes, it is useful to consider the case where monodisperse particles are scavenged by a distribution of raindrop sizes. A simple geometrical argument leads to the familiar form for the differential scavenging coefficient corresponding to a given single particle size:

$$
k(a, R)=\int_{0}^{\infty} \pi R^{2} E(a, R) F(R) d R,
$$

where $a$ is the particle radius, $E(a, r)$ is the collection efficiency (fraction of the particles encountered by the falling raindrop which is removed*), and $F(R) d R$ is the flux (number/area-time) of raindrops with radii $R$ to $R+d R$.

Polydispersity of the particle sizes can be treated through a second integration, ${ }^{1}$ but for reasons 1 isted below we will approximate the particle size spectrum by a mean radius, and use the monodisperse form for sample calculations.

Theoretical estimates based on evaluation of (2) thus require the specification of a mathematical form for the collection efficiency as a function of $a$ and $R$, and a suitable raindrop size distribution or probability

*For simplicity we are assuming perfect retention of particles scavenged by raindrops. Thus the theoretical efficiencies, which are actually colizision efficiencies, are here equated to and called collection efficiencies. 

density function. As will be shown below, the important condensate droplet sizes are in the several $\mu \mathrm{m}$ range, so the choice of collection efficiency will be limited to a consideration of the inertial scavenging process, which is the predominant mechanism for removal of particles larger than about $1 \mu \mathrm{m}$ radius.

Slinn ${ }^{2}$ has derived a convenient form for the inertial collection efficiency, a semiempirical expression fitted to experimental results of Walton and Woodcock ${ }^{3}$ and the numerical calculations of Fonda and Herne. ${ }^{4}$ The form is

$$
E(\hat{a}, R)=\left(\frac{S-1 / 12}{S+7 / 12}\right)^{3 / 2},
$$

where $S$ is the Stokes parameter

$$
S=\frac{2 a^{2} \rho_{w} V_{t}}{9 R \rho_{a}{ }^{\nu}}
$$

In (4), $\rho_{W}$ and $\rho_{a}$ are the mass densities of the particles and air, respectively, $v_{t}$ is the raindrop terminal velocity and $\nu$ is the kinematic viscosity of air. 


\section{CALCULATION OF RAINFALL ENHANCEMENT}

Evaluation of (2) with the substitution of a suitable raindrop flux distribution and collection efficiency given by (3) cannot generally be done analytically; numerical integration has been performed ${ }^{1}$ using lognormal raindrop distributions. For present purposes, however, a computer program ${ }^{5}{ }^{6}$ which utilizes a discrete raindrop spectrum to provide accurate approximations was used. For a given raindrop size $R_{i}$ characterizing a discrete size interval $i$, (2) reduces to

$$
k_{i}=k\left(a, R_{i}\right)=\frac{3 E\left(a, R_{i}\right) J_{i}}{4 R_{i}}
$$

$J_{i}$ is the rainfall rate (length/time) for raindrops of size $R_{i}$, given by

$$
\mathrm{J}_{\mathbf{i}}=\frac{4}{3} \pi \mathrm{R}_{\mathbf{i}}{ }^{3} \mathrm{~F}_{\mathbf{i}}
$$

where $F_{j}$ is the flux of raindrops of radius $R_{j}$.

Since we are interested in the enhancement of rainfall by scavenging of water droplets, it is useful then to consider the mass flux of water to the ground (mass/area.time or length/time) as a result of scavenging. The flux at a point on the ground $(x, y)$ for the raindrops $R_{j}$ is given by $k x_{w}(x, y)$, where

$$
x_{w}(x, y)=\int_{0}^{\infty} x(x, y, z) d p
$$

is the integral of the air concentration of water droplets $x(x, y, z)$ along the path $p$ of the raindrop. That is, the total mass of plume droplets in a unit area column along the path of the raindrop is $x_{w}, k$ is the fraction per unit time removed, so the flux to the ground is $k x_{w}$. But the flux is also $C_{i} J_{i}$, where $C_{i}$ is the concentration (mass/volume) of scavenged water in the raindrop. Thus, at a point on the ground $(x, y)$

$$
c_{i}(x, y)=\frac{k_{i} x_{w}(x, y)}{J_{i}}=\frac{3 E\left(a, R_{i}\right) x_{w}(x, y)}{4 R_{i}} .
$$



The enhancement of rainfall, or fractional increase in mass of water deposited on the ground is equal numerically to the concentration of scavenged water in $\mathrm{g} / \mathrm{cm}^{3}$ units, since the concentration of water in the raindrop alone $\left(\rho_{w}\right)$ is $1 \mathrm{~g} / \mathrm{cm}^{3}$ :

$$
\text { Fractional Enhancement }=\frac{C_{i}}{P_{w}} \quad \text { (dimensionless). }
$$

The evaluation of the net enhancement of rainfall due to scavenging by the whole raindrop spectrum at a point $(x, y)$ is the mass weighted sum of the individual concentrations $C_{j}$ :

$$
c(x, y)=\frac{\sum_{i=1}^{n} c_{i}(x, y) f_{i} R_{i}{ }^{3}}{\sum_{i=1}^{n} f_{i} R_{i}{ }^{3}}
$$

In (10), $f_{j}$ is the fraction of the total number of raindrops residing in the interval $i, n$ is the total number of intervals, and $c_{i}(x, y)$ is given by (8).

Evaluation of (10) at a point on the plume centerline $(x, 0)$ gives the peak rainfall enhancement; a subsequent integration or summation of $c(x, y)$ in the cross-plume direction y leads to a cross-plume integrated enhancement. This, divided by an effective total width of the plume (or scavenging deposition pattern) $y$ gives an estimate of the average rainfall enhancement at a distance $x$ :

$$
C(x)=\frac{\int_{-\infty}^{+\infty} C(x, y) d y}{y} .
$$

The following calculations of cross-plume average enhancement were done by a summation over discrete points $y_{i}$ similar in form to (10). The effective total width of the deposition pattern was taken as 6 times the standard deviation in the $y$ direction of the plume model chosen (see below) at the appropriate downwind distance $x$. 
. 
The mathematical form for the air concentration of condensate droplets chosen was a bivariate normal plume model: ${ }^{7}$

$$
\begin{aligned}
x(x, y, z) & =\frac{Q}{2 \pi \sigma \sigma_{y} z^{u}} \exp \left[-\frac{1}{2}\left(y / \sigma_{y}\right)^{2}\right]\left\{\exp \left[-\frac{1}{2}\left(\frac{z-h}{\sigma_{z}}\right)^{2}\right]\right. \\
& \left.+\exp \left[-\frac{1}{2}\left(\frac{z+h}{\sigma_{z}}\right)^{2}\right]\right\},
\end{aligned}
$$

where $Q$ is the source term $(\mathrm{g} / \mathrm{sec})$,

$\sigma_{y}, \sigma_{z}$ are the standard deviations of plume spread in the cross-plume $y$ and vertical $z$ directions $(\mathrm{cm})$,

$u$ is the wind speed $(\mathrm{cm} / \mathrm{sec})$, and

$h$ is the source height $(\mathrm{cm})$.

The standard deviations of plume spread used are those of Smith and Singer ${ }^{8}$ for neutral conditions, which best approximate conditions during frontal (nonconvective) rainfall:

$$
\begin{aligned}
& \sigma_{y}=0.69 x^{0.86} \\
& \sigma_{z}=0.63 x^{0.86}
\end{aligned}
$$

$\left(\sigma_{y}, \sigma_{z}\right.$, and $x$ in $\left.\mathrm{cm}\right)$.

The use of this point-source model directly for a cooling tower plume is inappropriate, since the source (the cooling tower mouth) is far from being a point. To approximate the area source of the cooling tower exit, a virtual source point, as illustrated in Figure 1 , was determined as follows. At the real source, the plume was assumed to have diffused from a point at $x=0$ to $x=x_{r}$, where the mouth diameter $W$ encompasses $6 \sigma_{y}$ of the piume. Thus

$$
W=6 \sigma_{y}\left(x_{r}\right)=4.116 x_{r}^{0.86} .
$$




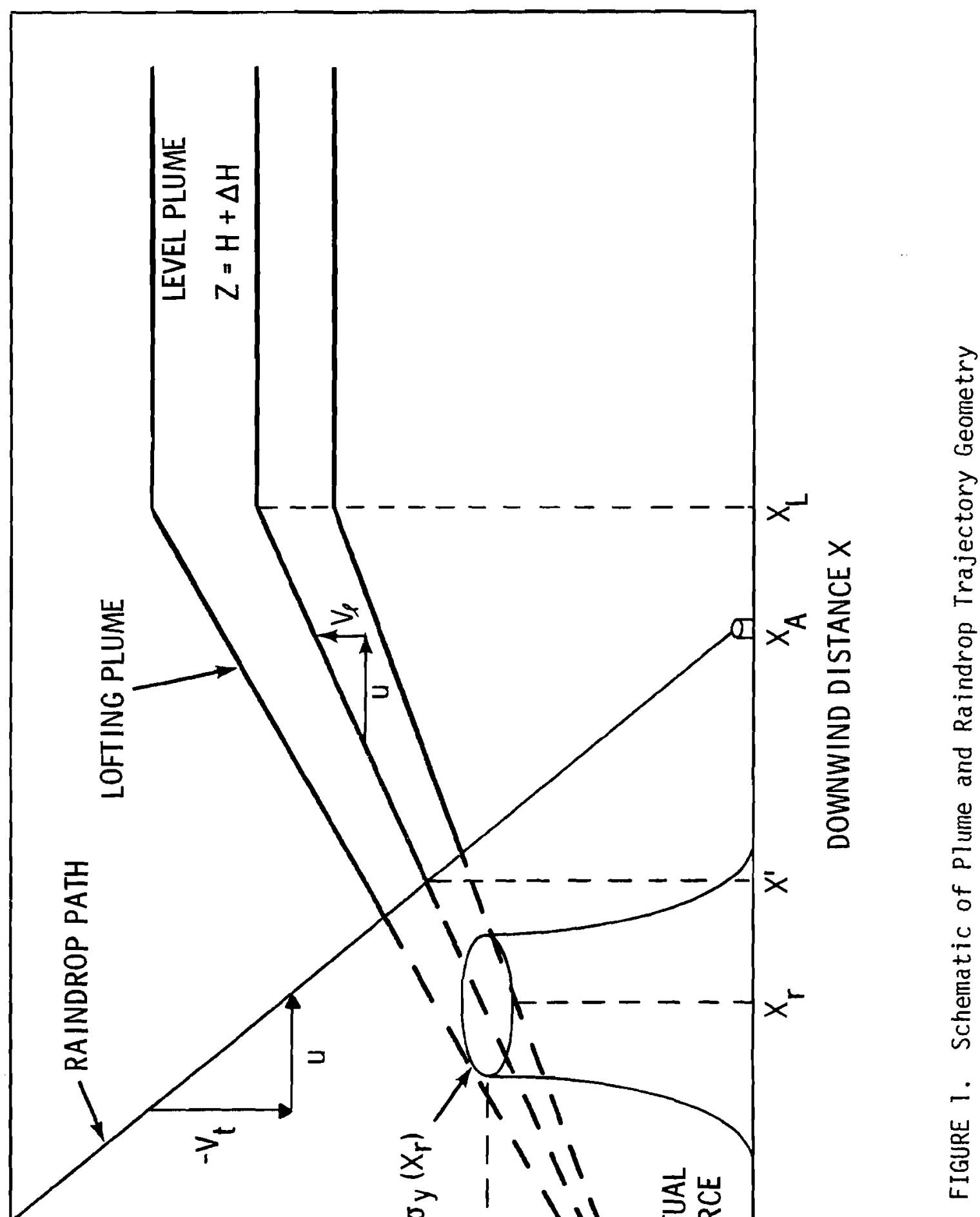

Z N0II $\forall \wedge \exists 7 \exists$ 


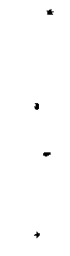


In addition, the plume is assumed to be rising linearly at an average velocity $v_{1}$ such that the virtual source height is defined by

$$
H^{\prime}=H-\frac{x_{r} V_{1}}{u}
$$

where $H$ is the true height of the cooling tower. Combining (14) and (15),

$$
\begin{gathered}
x_{r}=\left[\frac{W}{4.116}\right]^{1.16} \\
H^{\prime}=H-\left[\frac{W}{4.116}\right]^{1.16} \frac{v_{1}}{u} .
\end{gathered}
$$

The lofting plume is assumed to rise to an elevation $H+\Delta H$, at downwind distance $x_{L}$, where it levels off. $\Delta H$ is evaluated as a function of temperature lapse rate, condensate exit temperature and wind speed $u .{ }^{9}$ Thus, use of (12) to describe the plume involves definition of $x$ as the downwind distance from the virtual source (where the real sampling distance of interest, the distance from the real source, is $x_{A}-x_{r}$ ) and use of a plume height which increases with $x$ as follows:

$$
\begin{array}{ll}
h=H^{\prime}+\frac{x V_{1}}{u} & x<x_{L} \\
h=H+\Delta H & x \geq x_{L} .
\end{array}
$$

The plume-derived quantity of interest for scavenging calculations (cf. (8)) is $x_{i N}\left(R_{j}\right)$, the raindrop-path integral of (12). For vertically falling raindrops this is expressed by the vertical integral

$$
x_{v}(x, y)=\frac{Q}{\sqrt{2 \pi} \sigma_{y}(x) u} \exp \left[-\frac{1}{2}\left(\frac{y}{\sigma_{y}(x)}\right)^{2}\right] \text {. }
$$

But raindrops never fall vertically if the wind speed is above zero. The trajectories of raindrops are approximated here as merely the resultants 

of the wind speed and terminal velocity (a function of raindrop size) vectors (Figure 1). The paths of a collection of raindrops of various sizes, all of which fall at the sampling point $x_{A}$, thus cross the plume at various distances from the source, "seeing" different plume shapes and total mass of cooling tower droplets. Indeed, some of the raindrops close to the real source will pass under the source, and be deposited at $x_{A}$ without scavenging anything.

Evaluation of the raindrop path integral $x_{w}$ can be done analytically for the paths as defined in Figure 1, but a good approximation to that rather complicated process involves use of (19) to derive $x_{W}$, where the distance $x$ involved is different from the sampling distance $x_{A}$. The value of $x$ used is that distance where the raindrop crosses the plume center line on the way to deposition at $x_{A}$. The vertical integral at that point is a generally close approximation to the integral along the slanted path passing through that point. The plume centerline crossing distance $x^{\prime}$ is defined by the plume geometry and the trajectory as follows:

$$
x^{\prime}\left(R_{i}\right)=\left[x_{A}+\frac{H^{\prime} u}{V_{t}\left(R_{i}\right)}\right] /\left[1-\frac{V_{1}}{V_{t}\left(R_{i}\right)}\right] .
$$

In the calculation process used here, then, (19) is evaluated at $x^{\prime}$ for each $R_{j}$, the concentration derived from (8), and the subsequent raindrop spectrum-mean concentration and cross-plume average concentration (enhancement) by (10) and (11). When $x^{\prime}<x_{r}$, the drop is assumed to have missed the source and the concentration is set to zero. If $x^{\prime}>x_{L}$, $x^{\prime}$ is constrained by holding the corresponding plume elevation to $H+\Delta H$. The terminal velocity expression used is an empirical expression 11 fitted to the data of Gunn and Kinzer. ${ }^{32}$ 



\section{SAMPLE CALCULATIONS}

The geometrical, meteorological, and source data listed in Table 1 were used to make sample calculations of condensate droplet scavenging and estimates of rainfall enhancement. The model cooling tower used is a typical modern natural draft tower: the source term for condensate was derived from thermodynamic considerations detailed in Appendix I, and the mass mean droplet radius taken from measurements described in Appendix II.

For a particular tower and source term $Q_{0}$, the major meteorological variables are wind speed, rainfall rate, and raindrop size spectrum. Three choices of $u$ and two of $\mathrm{J}$ were chosen to test; only one raindrop spectrum was used, that of a typical Pacific Northwest frontal rain. This spectrum (Table 2) was derived from numerous measurements in pre-frontal rains of low to moderate rate $(<5 \mathrm{~mm} / \mathrm{hr})$. For heavier rains and/or convective showers, a somewhat different spectrum may apply; however, the raindrop size dependency of the inertial collection efficiency is weak for most drop sizes encountered naturally. ${ }^{1}$ Thus for rain spectra with a different overall mean radius than that used here (mass mean radius $20.045 \mathrm{~cm}$ ), one may apply the $\mathrm{R}^{-1}$ dependency of (5) to make estimates of departure.

Table 3 is a list of the plume parameters derived from the input data for the various wind speed cases. These and the other data were used to estimate centerline rainfall enhancement, cross-plume average enhancement, and plume depletion at downwind distances (actual) ranging from $100 \mathrm{~m}$ to $50 \mathrm{~km}$. These are expressed as percentages and plotted in Figures 2-11. Because of the rather high rate of removal of water from the plume in all cases, it was necessary to account for depletion of the plume by scavenging as $x$ was increased. This was done using the exponential decay expression (1). If $X_{A i}$ is the ith sampling distance considered

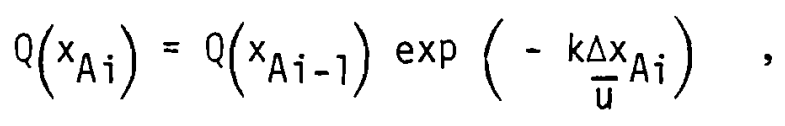



TABLE 1. Input Parameters Used in Calculations of Rainfall Enhancement

\begin{tabular}{|c|c|c|c|}
\hline & Item & Value & Units \\
\hline \multirow[t]{5}{*}{ Source } & Liquid water source & $1.7 \times 10^{5}$ & $\mathrm{~g} / \mathrm{sec}$ \\
\hline & Cooling tower height & 150 & m \\
\hline & " mouth diameter & 80 & $\mathrm{~m}$ \\
\hline & Loft velocity (average) & 2.5 & $\mathrm{~m} / \mathrm{sec}$ \\
\hline & Plume droplet radius (mass mean) & 5 & $\mu m$ \\
\hline Meteorology & Wind speed & $1,5,10$ & $\mathrm{~m} / \mathrm{sec}$ \\
\hline & Rainfall rate & 1,5 & $\mathrm{~mm} / \mathrm{hr}$ \\
\hline
\end{tabular}

TABLE 2. Discrete Raindrop Spectrum Used in Calculations of Rainfal1 Enhancement

$\begin{array}{lc}\text { Radius, cm } & \begin{array}{l}\text { Fraction of total } \\ \text { number in interval }\end{array} \\ 0.0095 & 0.18 \\ 0.013 & 0.14 \\ 0.0175 & 0.18 \\ 0.0235 & 0.20 \\ 0.032 & 0.14 \\ 0.0435 & 0.09 \\ 0.059 & 0.05 \\ 0.080 & 0.013 \\ 0.1075 & 0.006 \\ 0.1475 & 0.001\end{array}$



TABLE 3. Plume Parameters Derived From Input Data of Table 1, and Geometry of Figure 1

\begin{tabular}{|c|c|c|c|}
\hline \multirow[t]{2}{*}{ Parameter } & \multicolumn{3}{|c|}{ Value (meters) for wind speed $u$} \\
\hline & $1 \mathrm{~m} / \mathrm{sec}$ & $5 \mathrm{~m} / \mathrm{sec}$ & $10 \mathrm{~m} / \mathrm{sec}$ \\
\hline$H^{\prime}$ & -13.2 & 117 & 134 \\
\hline$x_{r}$ & 65.3 & 65.3 & 65.3 \\
\hline$x_{L}$ & 308 & 900 & 1430 \\
\hline$\Delta H$ & 770 & 450 & 350 \\
\hline
\end{tabular}

where $\Delta x_{A j}=x_{A i}-x_{A j-1}$. Although the actual distance at which scavenging takes place is some mean $x^{\prime}$ (cf.(19)), the $x_{A}{ }^{\prime} s$ were used since the difference in distance between the $i$ and $i-1$ points are nearly the same for each. $k$ in (21) is a simple mean scavenging coefficient $\left[\left(k_{A i}+k_{A i-1}\right) / 2\right]$ where the $k_{i}$ values are derived from the cross-plume integrated concentrations. In practice, these are constant for all $x_{A}$ large enough so that all raindrops are involved in the calculation (no "under cutting" of the real source). This follows from the fact that $k$ is not a function of $Q$, nor does it vary as long as the raindrop spectrum and particle size are fixed.

As Figures 2-4 show, the plume centerline rainfall enhancement values are clearly significant close to the source for all three wind cases and both rainfall rate cases. For $u=1 \mathrm{~m} / \mathrm{sec}$, the highest centerline enhancement occurs within the starting sampling distance $(100 \mathrm{~m})$, and is apparently very large. The peak values for $u=5$ and $10 \mathrm{~m} / \mathrm{sec}$ are 46 and 17 percent, respectively. These peaks occur near the value of $x$ where all of the raindrops are involved in the calculation. According to (8), it should be noted, the removal rate is greatest for the smallest values of $R_{i}$. The effect of wind speed here, of course, is just that more time is allowed in reaching a given distance, so that more water droplets are removed by that point. The variation as a function of rainfall rate $J$ arises solely from the inclusion of depletion of the source by prior 



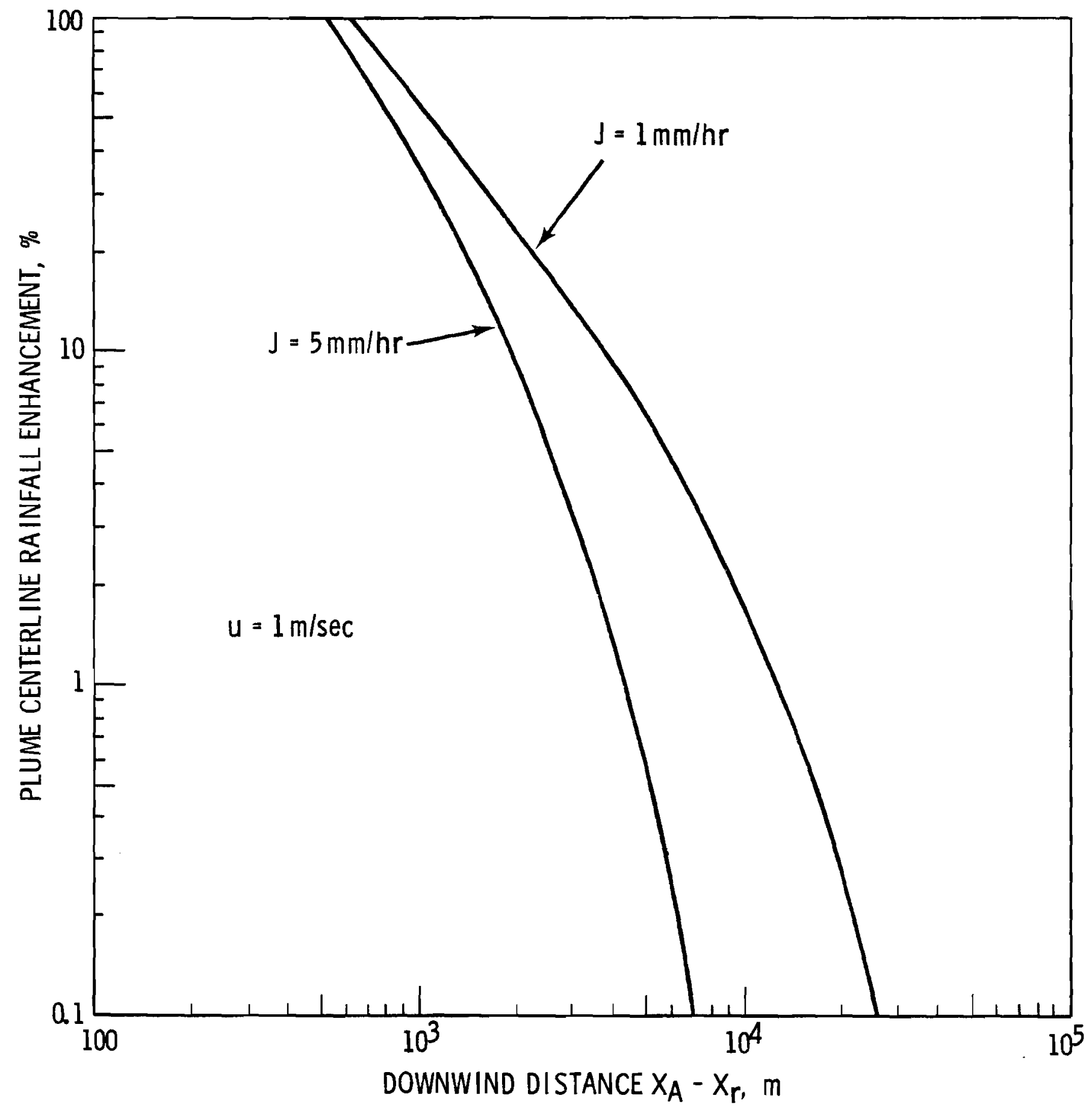

FIGURE 2. Rainfall Enhancement (Concentration of Scavenged Condensate) at the Plume Centerline vs. True Downwind Distance:

Cases of $u=1 \mathrm{~m} / \mathrm{sec}$ and $\mathrm{J}=1$ and $5 \mathrm{~mm} / \mathrm{hr}$ 



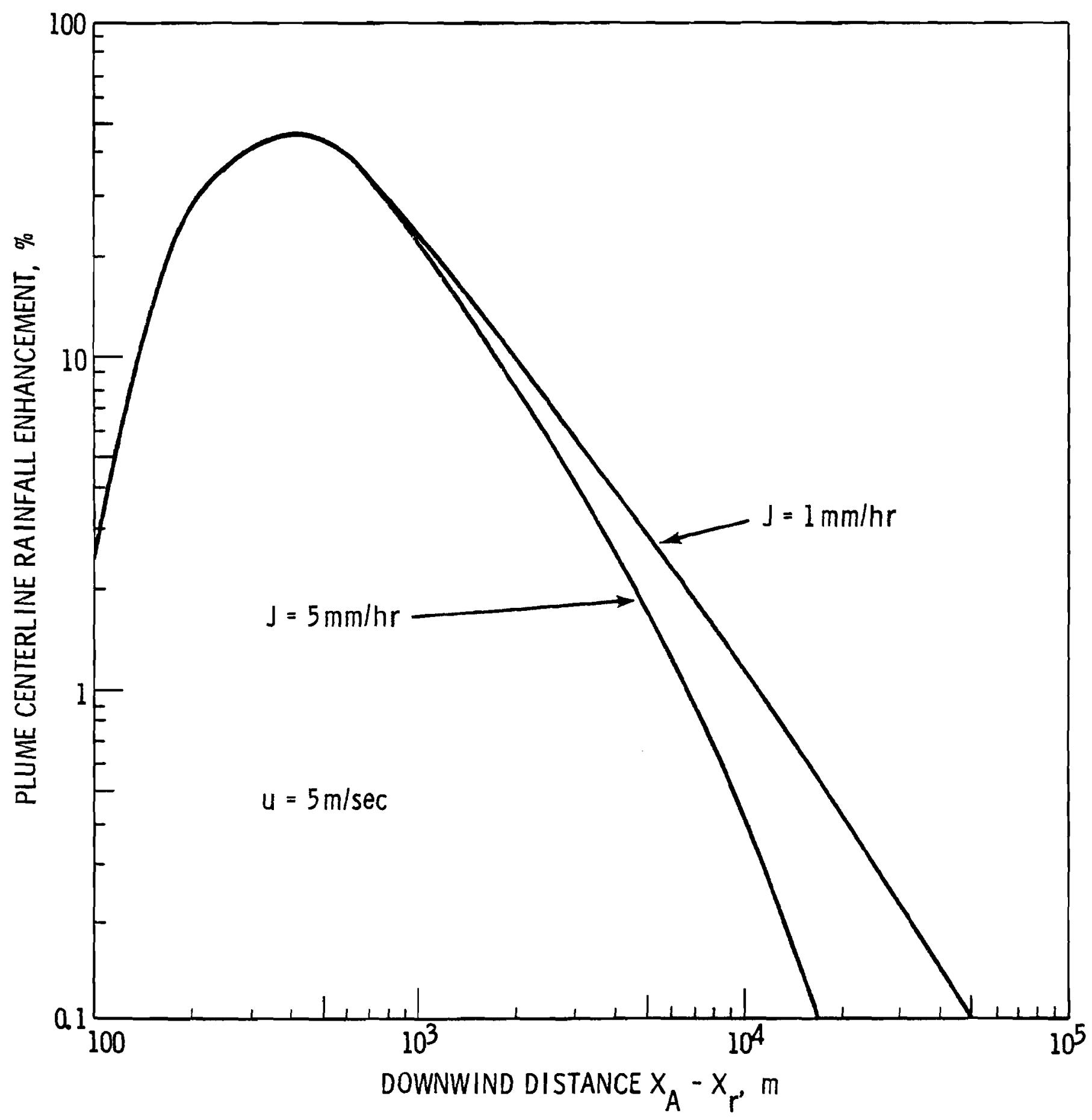

FIGURE 3. Rainfa11 Enhancement (Concentration of Scavenged Condensate) at the Plume Centerline vs. True Downwind Distance: $u=5 \mathrm{~m} / \mathrm{sec}$ 


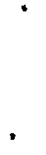




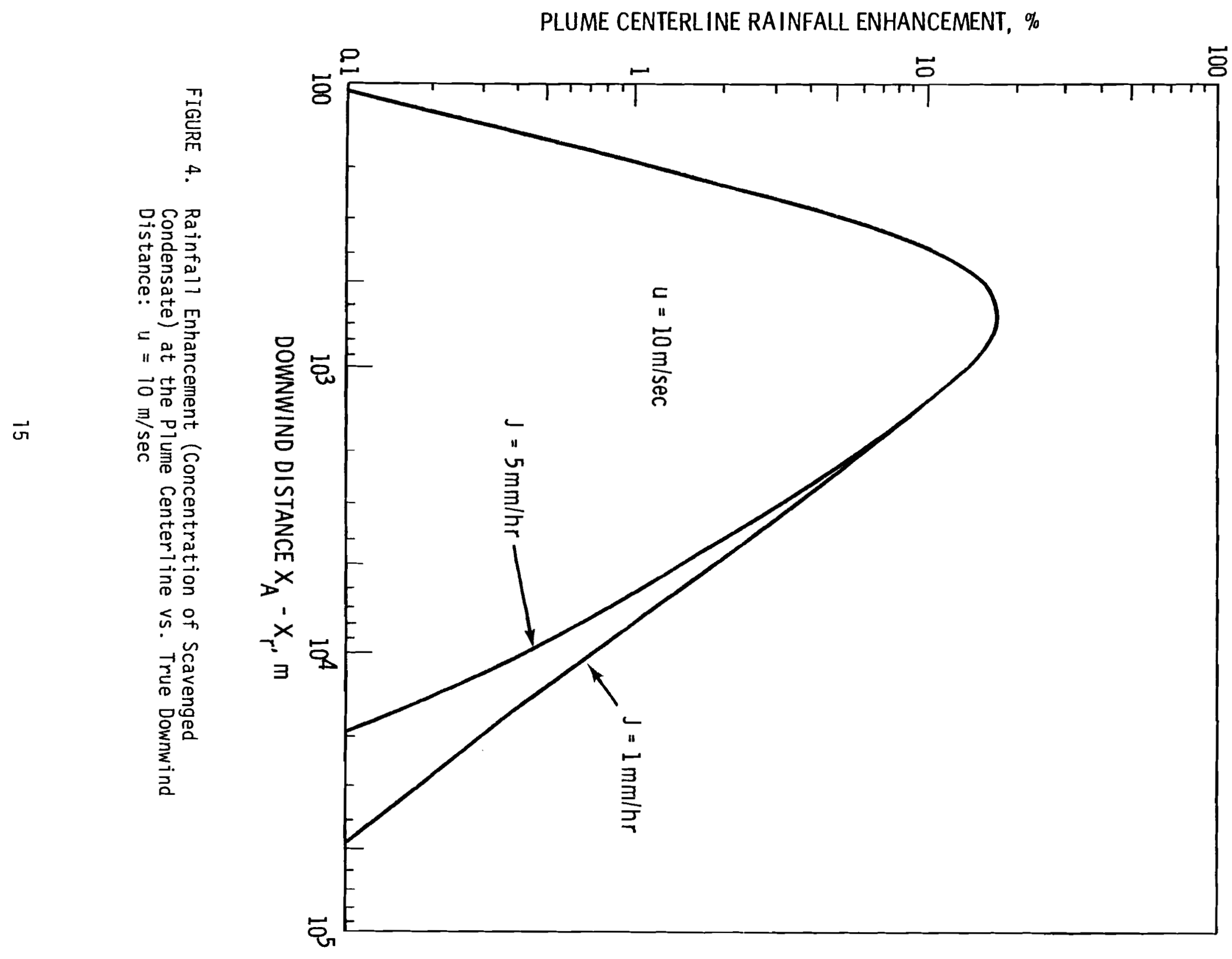



scavenging. In the absence of depletion, there would be no difference in the concentrations for different $J$ input.

It should be noted that the scavenging and resulting rainfall enhancement calculated at the plume centerline is often sufficiently large to imply an actual growth in the mass of the raindrops. This apparent growth in principle can increase the size of the raindrops to such an extent that the collection efficiency is changed (cf $(3)$ ). However, the raindrop size is related to the one-third power of the mass, so a considerable mass increase is required before this effect becomes significant, especially since, through the Stokes parameter $S$, the collection efficiency dependency on $R$ is rather weak. In fact, in none of the calculations done here was this apparent growth great enough to warrant accounting for the change in the collection efficiency due to raindrop growth.

The cross-plume-integrated rainfall enhancement (Figures 5 through 7), or overall average enhancement at the given distance, generally reflects the character of the centerline value. In fact, the use of a bivariate normal plume allows that the cross-wind value for each $R_{i}$ be proportional to the product of the centerline concentration and $\sigma_{y}\left(x^{\prime}\right)$. However, each raindrop size considered has a different $x^{\prime}$ value $\left(x^{\prime}<x_{A}\right)$; thus the cross-plume deposition pattern for the whole raindrop spectrum is not Gaussian. Figure 8 compares the cross-plume rainfall enhancement profile for one case $\left(u=5 \mathrm{~m} / \mathrm{sec}, J=1 \mathrm{~mm} / \mathrm{hr}, x_{A}-x_{r}=400 \mathrm{~m}\right.$ ) with that which would result if all the drop size categories were assumed to be falling vertically. The curve for the case where slanted raindrop trajectories are considered is more peaked because the raindrops cross the plume at a point where it is less diffuse than it is above the point where they land. Correspondingly, the edge values are reduced because of the narrower plume "seen." The areas under the two curves of Figure 8 are identical, since the integral of the plume over both vertical and horizontal dimensions is $Q\left(x_{A}\right)$, and the distance of plume travel for depletion purposes was defined, for convenience, as $x_{A}-x_{r}$ in both cases. 



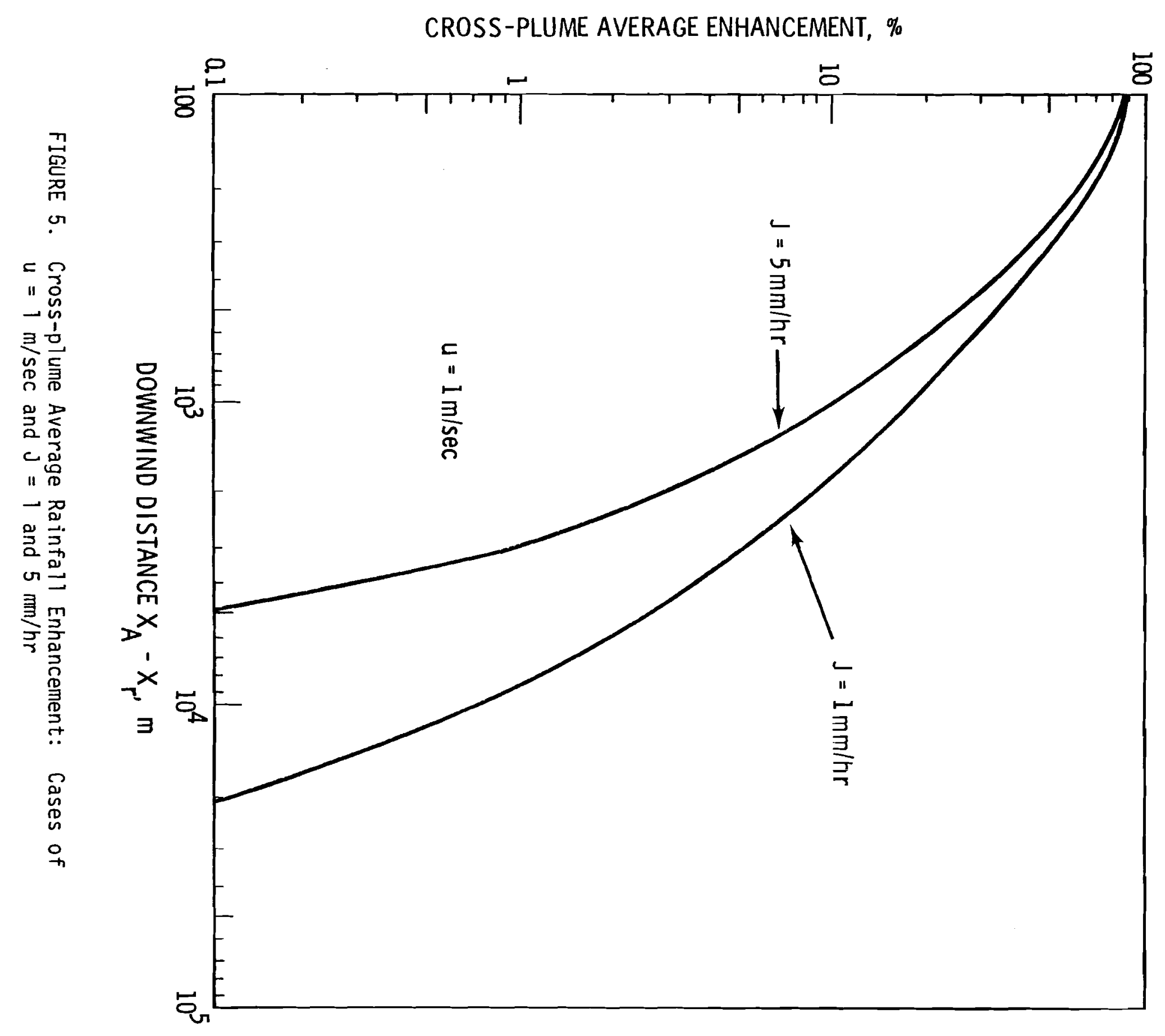




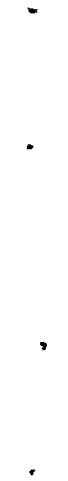


CROSS-PLUME AVERAGE ENHANCEMENT, \%

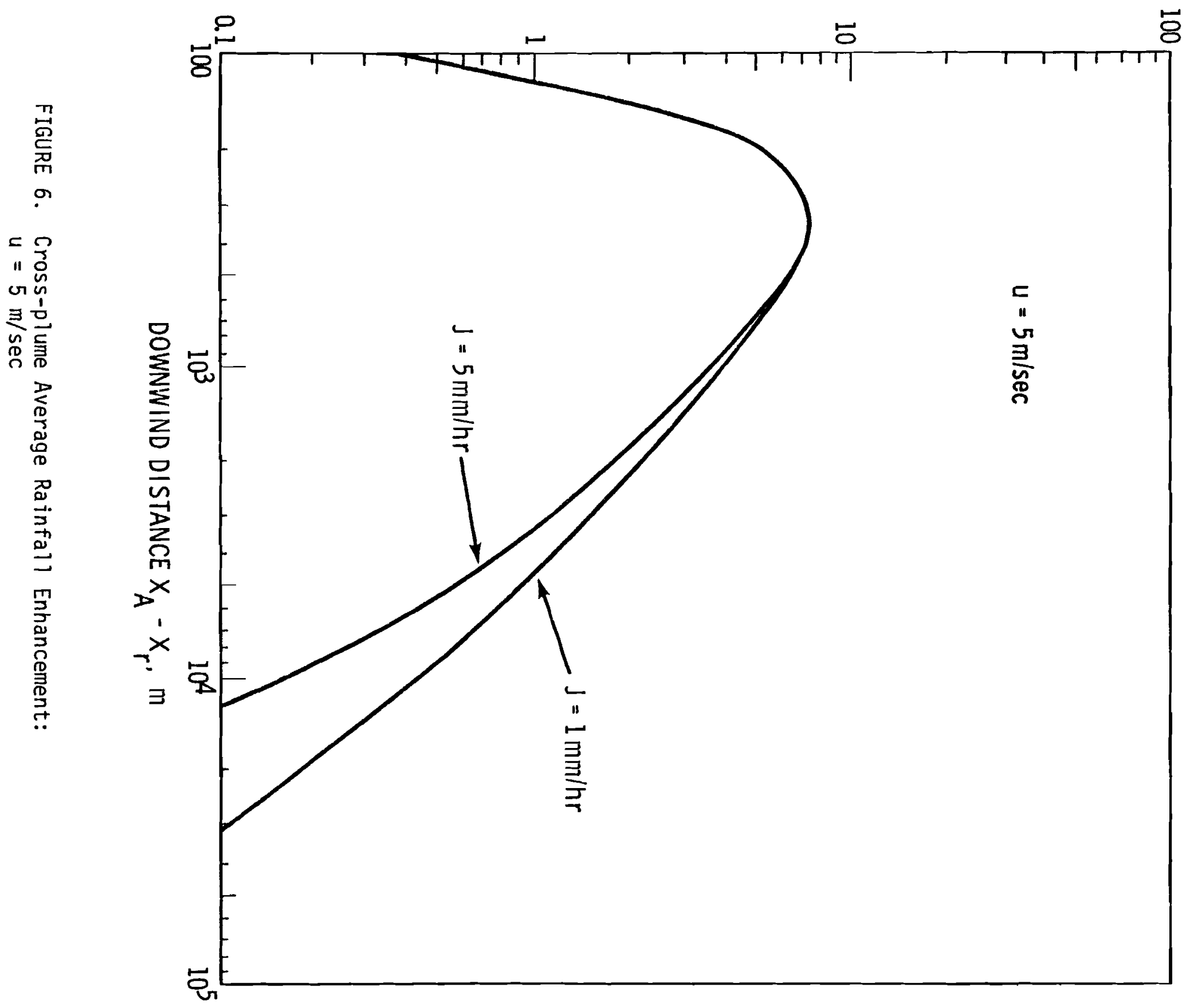


, 


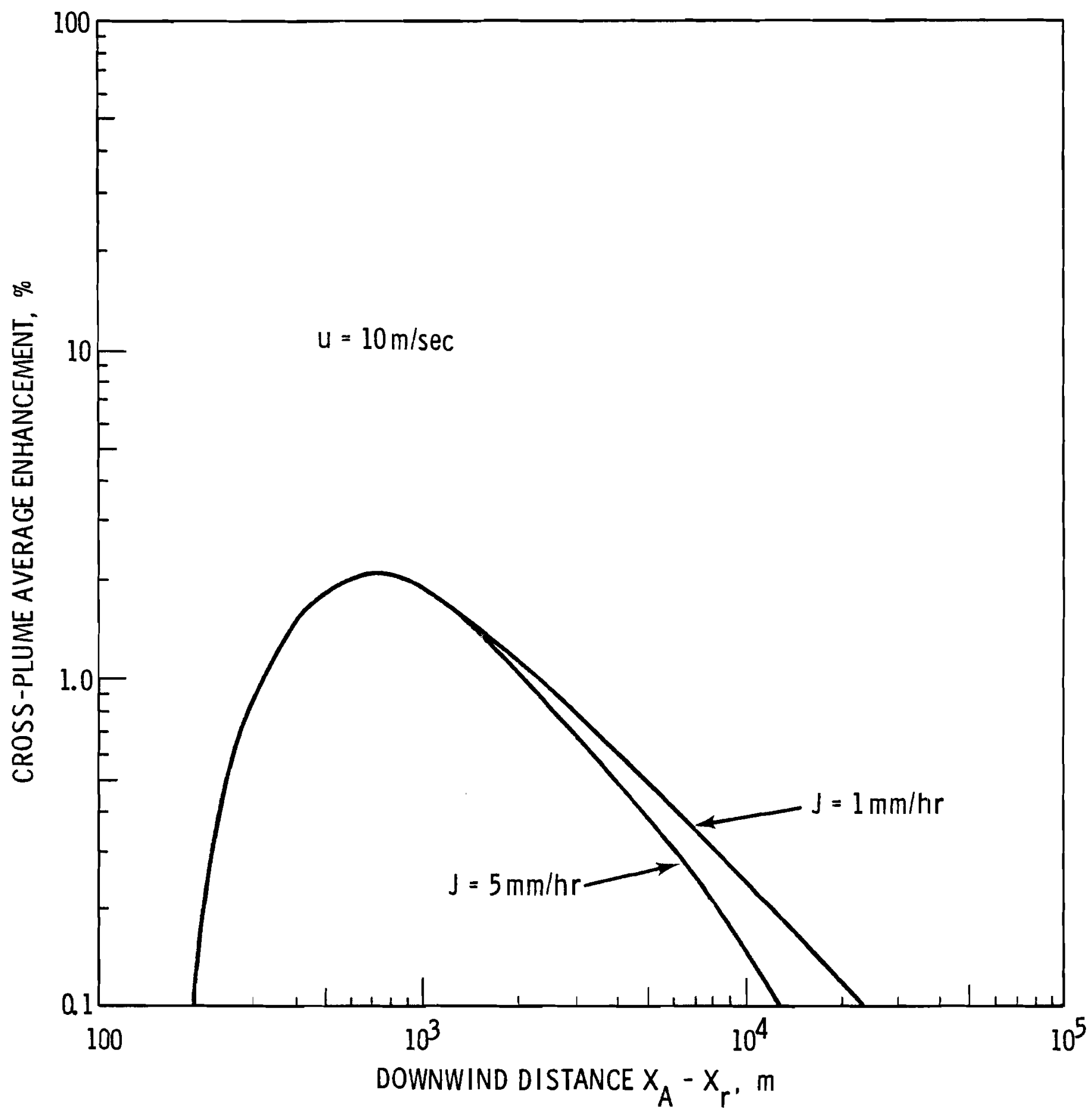

FIGURE 7. Cross-plume Average Rainfall Enhancement: $u=10 \mathrm{~m} / \mathrm{sec}$ 


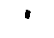




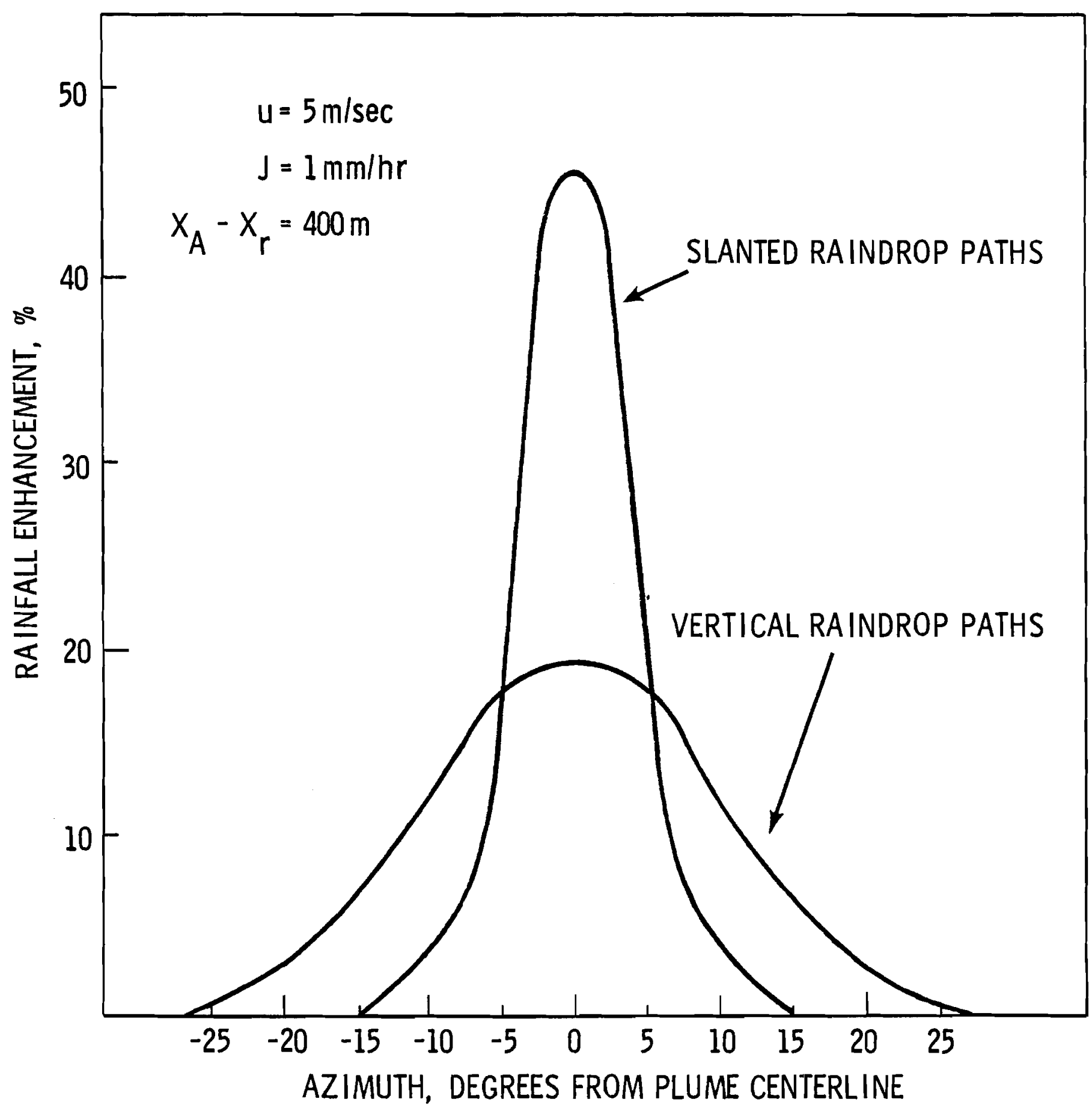

FIGURE 8. Examples of Cross-plume Rainfall Enhancement Patterns When Calculation is Done Using Either Slanted Raindrop or Vertical Raindrop Trajectories 


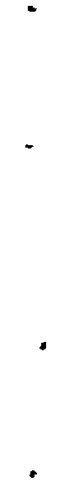


The cumulative removal of cooling tower condensate as a function of distance downwind (Figures 9-11) is significant for all cases, with plume "half-distances" ranging from about $600 \mathrm{~m}$ to $25 \mathrm{~km}$. It should be noted that the decay shown is essentially exponential (cf. (21)) with time constant $k$ ( $k$ being proportional to $\mathrm{J}$ ). The value of $k / J$, or fraction of the source removed per unit depth of rainfa11, for the present rain spectrum and droplet size is about $1 \mathrm{~mm}^{-1}$. 



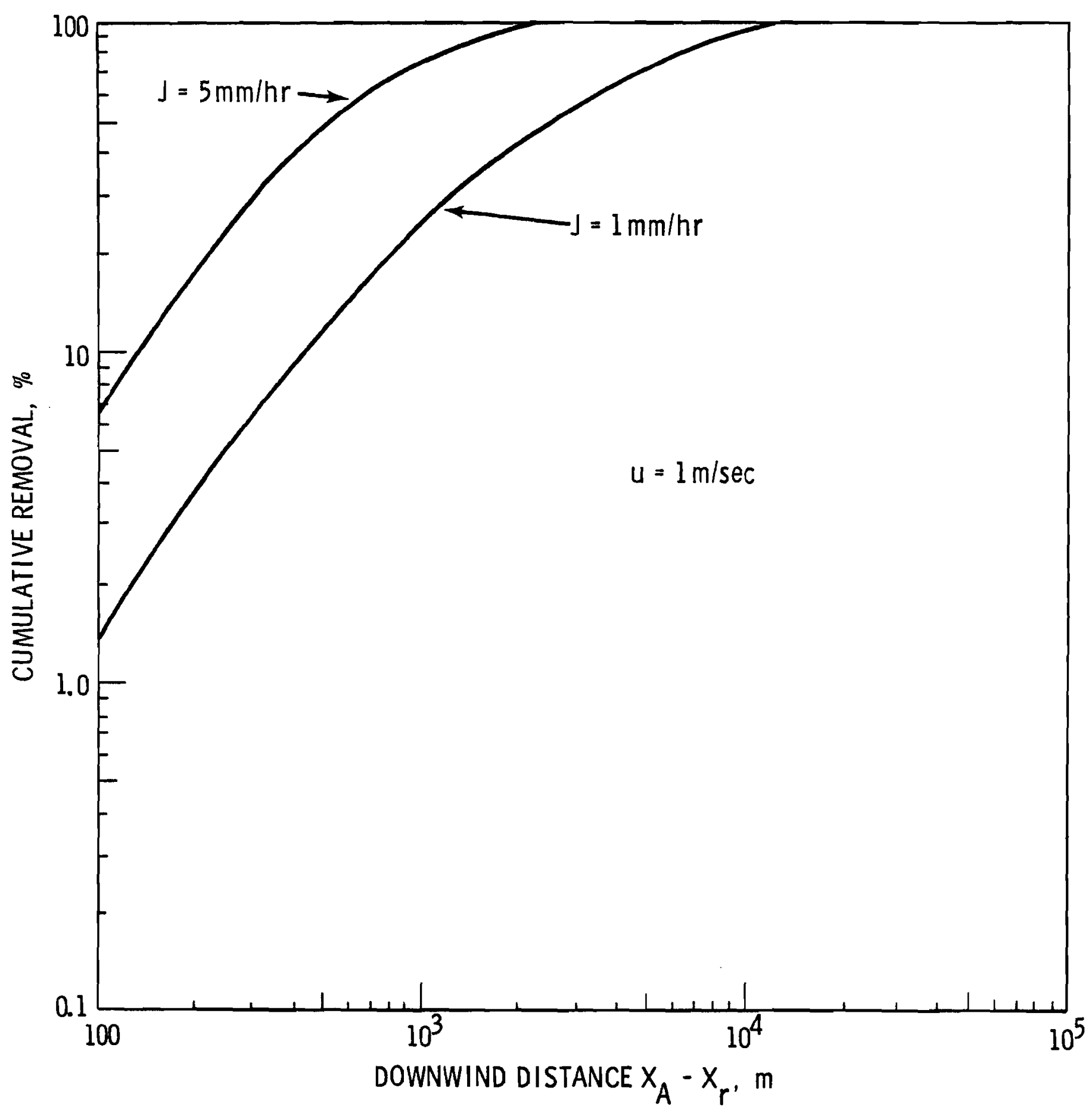

FIGURE 9. Cumulative Removal of Condensate by Scavenging: Cases of $u=1 \mathrm{~m} / \mathrm{sec}$ and $\mathrm{J}=1$ and $5 \mathrm{~mm} / \mathrm{hr}$ 



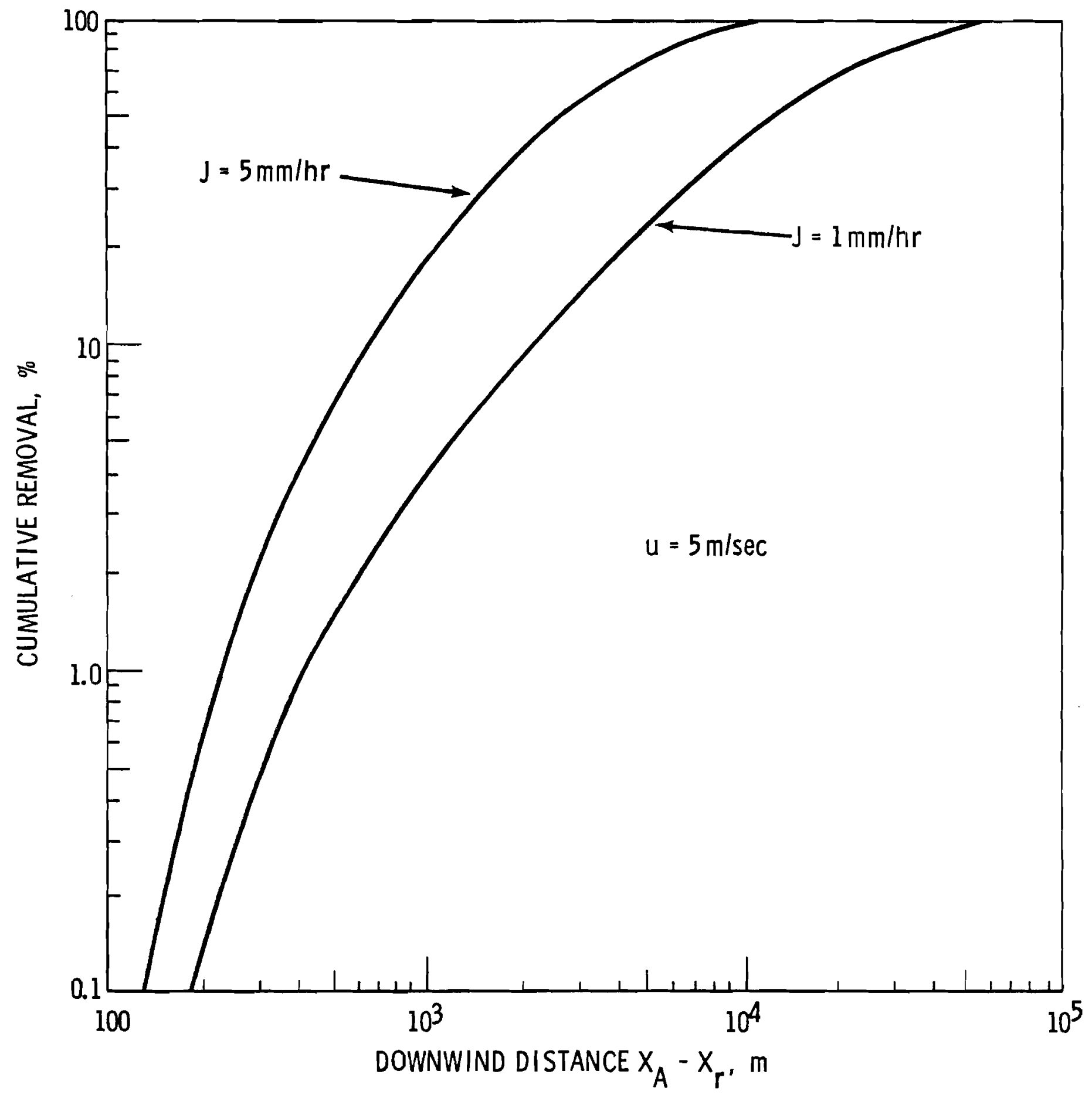

FIGURE 10. Cumulative Removal of Condensate by Scavenging: $u=5 \mathrm{~m} / \mathrm{sec}$ 


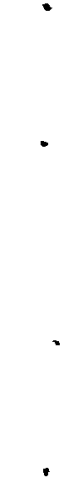




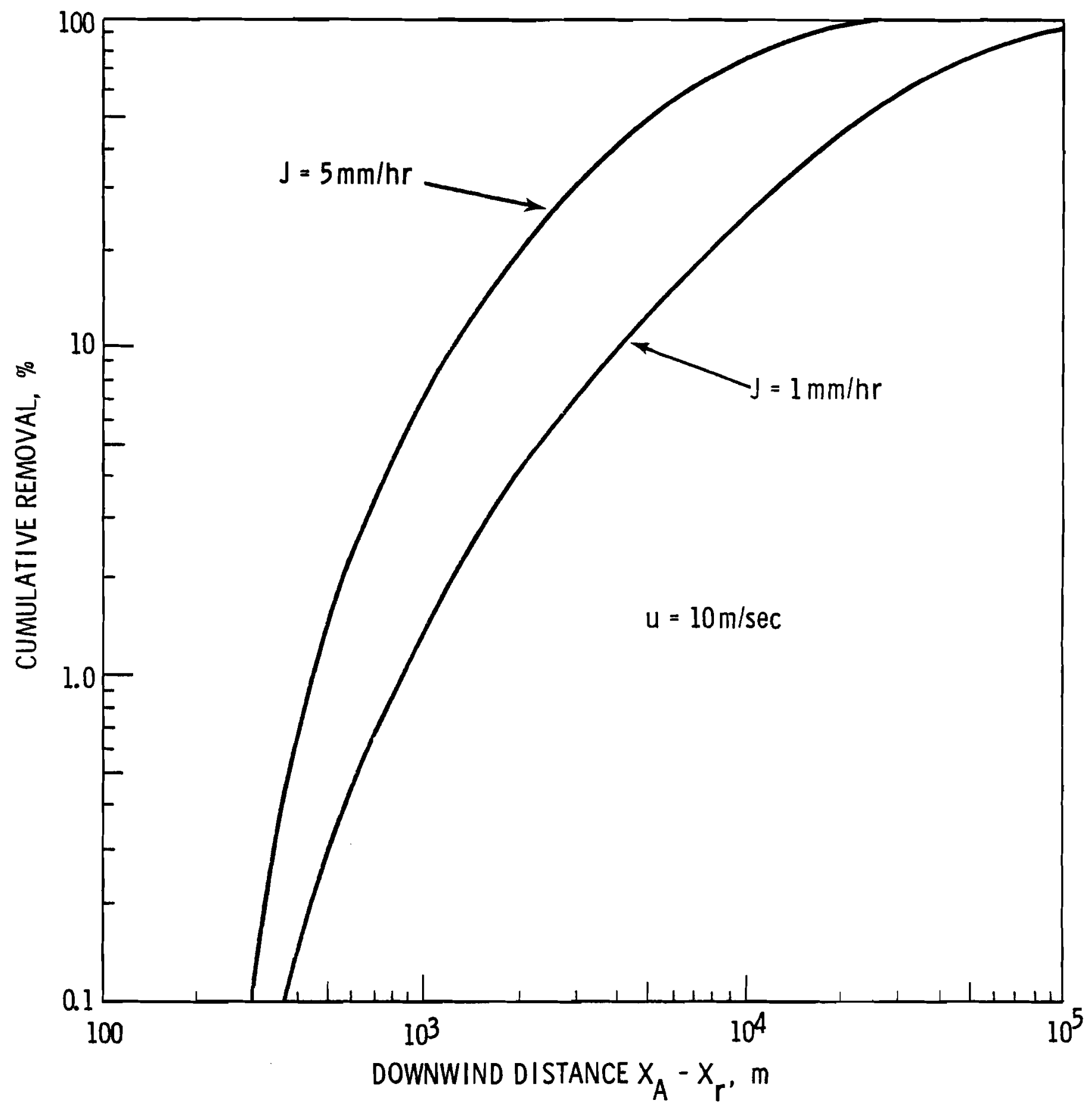

FIGURE 11. Cumulative Removal of Condensate by Scavenging: $u=10 \mathrm{~m} / \mathrm{sec}$ 


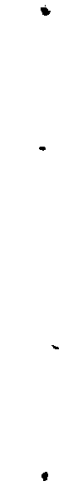




\section{CONCLUSIONS AND RECOMMENDATIONS}

The integral process of removal of cooling tower condensate by scavenging, leading to depletion of the plume in time downwind, is essentially independent of plume or raindrop trajectory geometry. This follows from the basic premise that the scavenging rate $k$ is a function of only the raindrop and condensate droplet size spectra. Integration over both these spectra leads to a fixed mean removal rate when the spectra are considered constant in time. The condensate size spectrum was represented by a single mean radius in the estimates made here; this was justified on the basis of the Gaussian appearance of the measured spectrum. Other spectra, typicaliy log normal, may be treated explicitly by the model. Although measurements and suppositions about the sizes (particularly the sizes containing the most mass of water) of cooling tower droplets vary, most point to a predominant size in the $\mu \mathrm{m}$ range. The $5 \mu \mathrm{m}$ radius used here is probably a good average value for cooling tower droplets in general. It should be noted as well that the mean collection efficiency for this size of droplet (and for typically sized raindrops) is about 0.75 . In the absence of extreme electric fields or other exotic scavenging mechanisins, the collection efficiency for droplets should not exceed 1.0. Thus, for spectra whose "scavenging effective" radius is in the $5 \mu \mathrm{m}$ or larger area, estimates made using inertial scavenging theory should not exceed those herein by a factor of 1.5 or so.

The effects on plume depletion of using different rain spectra should be less significant; the inertial collection efficiency is essentially independent of raindrop size, and the scavenging rate is inversely proportional to raindrop radius. For rainfall rates exceeding about $5 \mathrm{~mm} / \mathrm{hr}$, and for convective showers, the raindrop size spectrum may differ significantly from that used here. In general, larger raindrops will result in smaller collection efficiencies (cf. (3) and (4)) and a slower rate of removal (cf. (5)) per unit rainfall rate.

The plume and raindrop trajectory geometries will, on the other hand, affect the patterm of deposition of condensate droplets. In particular, 
$\cdot$
$\cdot$
$\cdot$
$\cdot$ 
the plume shape near the cooling tower mouth, and the character of the plume rise will profoundly affect the location and magnitude of the maximum rainfall erhancement. Use of more sophisticated cooling tower condensate plume models will probably result in better estimates of rainfall enhancement near the source.

Much of the information about plume configuration and, indeed, atmospheric conditions such as temperature profiles, turbulence, and condensate droplet spectra come from (by necessity) fair weather measurements. Complicating factors, such as low ceilings (plume disappearing into natural clouds) and stormy conditions, make measurements under actual precipitation conditions difficult, if not impossible. Therefore, it is questionable at this time whether it is useful to refine the model to include more detailed plume descriptions, because of the lack of experimental guidance under precipitation conditions.

Since there are normally considerable uncertainties in raindrop and condensate droplet spectra, turbulence (affecting the raindrop trajectories), and plume behavior, the deposition patterns estimated here should be considered order-of-magnitude. The two significant results, and those which should be measurable in the field, are: the overall significant rainfall enhancement and resultant rapid depletion of the plume; and the peakedness of the rainfall enhancement relatively near the cooling tower due to raindrops traversing a more concentrated, narrower plume than that directly above their deposition point.

We suggest two types of field experiments to examine the two features of the scavenging process noted above. The first involves a concentrated network of precipitation collectors, deployed on a short-term, precipitation event basis, arrayed in lines or arcs under the plume to detect the crossplume shape of the deposition pattern near the cooling tower. For the situation illustrated in Figures 6 and 8 , about 20 collectors at $2-1 / 2^{\circ}$ spacing at each of several distances downwind should be sufficient to detect the peakedness of the rainfall enhancement pattern. Given a rain of sufficient depth and relatively constant wind speed and direction, this could be done using ordinary buckets or funnel-and-bottle collectors. Many 
. 
similar experiments detecting scavenging of $\mathrm{SO}_{2}$ and other pollutants from power plants have been done successfully and practical1y5,6.

A second type of experiment could detect the degree of overall rainfall enhancement in the downwind area by monitoring precipitation over a longer period with an array of recording rain gauges. Given a fairly constant wind direction during precipitation, the typical situation of Figure 6 could be examined by using about 40 such gauges. This experiment probably would require data from a number of rainstorms in order to catch the proper conditions several times.

Selection of a proper site for these experiments is a very important practical consideration. Sufficient rainfall, preferably mostly of a frontal variety, is a requirement, as is a dependable wind direction during precipitation (the second experiment in particular would probably not be practical if more than an approximately 90 degree sector needs to be monitored). Also important are accessibility, reasonably flat terrain, and dependable operation of the cooling towers. 


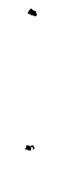




\section{REFERENCES}

1. Dana, M. Terry, and Jeremy M. Hales, "Statistical Aspects of the Washout of Polydisperse Aerosols," Atmos. Environ. 10:45-50, 1976.

2. Slinn, W. G. N., "Below Cloud Scavenging of Particles," In Pacific Northwest Laboratory Annual Report for 1974 to the USAEC Division of Biomedical and Environmental Research, Part 3. Atmospheric Sciences, BNWL-1950 PT3, 87-90, Battelle, Pacific Northwest Laboratories, Richland, WA, 1975.

3. Walton, W., and A. Woodcock, "The Suppression of Airborne Dust by Water Sprays," In Aerodynamic Capture of Particles, p. 129, Pergamon Press, 0xford, 1970.

4. Fonda, A., and H. Herne, The Aerodynamics Capture of Particles by Spheres, National Coal Board Min. Res. Est. Rep. No. 2068, 1957.

5. Dana, M. Terry, J. M. Hales, W. G. N. Slinn, and M. A. Wolf, Natural Precipitation Washout of Sulfur Compounds from Plumes, EPA-R3-73-047, Battelle, Pacific Northwest Laboratories, Richland, WA, 1973.

6. Hales, Jeremy M., Marvin A. Wolf, and M. Terry Dana, "A Linear Model for Predicting the Washout of Pollutant Gases from Industrial Plumes," AIChE Journal, $19(2): 292-297,1973$.

7. Slade, D. H., Ed., Meteorology and Atomic Energy, USAEC 68-60097, pp. 403-404, 1968.

8. Smith, M. E., and I. A. Singer, "An Improved Method of Estimating Concentrations and Related Phenomena from a Point Source Emission," J. Appl. Meteorol. 5:631-639, 1966.

9. Patrinos, A. A., and H. W. Hoffman, Atmospheric Effects of Nuclear Energy Centers (AENEC) Program. Annual Technical Progress Report for Period July 1975-September 1976, ORNL/TM-5778, Oak Ridge National Laboratory, Oak Ridge, TN, 1976.

10. Dana, M. Terry, "Below Cloud Precipitation Scavenging of Pollutant Plumes: Effect of Nonvertical Precipitation on Deposition Patterns," In Pacific Northwest Laboratory Annual Report for 1974 to the USAEC Division of Biomedical and Environmental Research, Part 3. Atmospheric Sciences, BNWL-1950 PT3, 91-98, Batte17e, Pacific Northwest Laboratories, Richland, WA, 1975.

11. Dingle, A. N., and Y. Lee, "Terminal Fallspeed of Raindrops," J. Appl. Meteorol. 11(5):877-879, 1972.

12. Gunn, R., and G. D. Kinzer, "Terminal Velocity of Fall for Water Droplets in Stagnant Air," J. Meteorol. 6:246, 1949. 
.

. 


\section{APPENDIX I}

\section{DETERMINATION OF APPARENT CONDENSATE FLOW RATE FROM A TYPICAL, LARGE NATURAL DRAFT COOLING TOWER}

The behavior of a saturated, heated plume relative to its liquid water content as it mixes with the ambient air is determined by the enthalpy, which is conservative. The wet bulb temperature completely defines the enthalpy and under saturated conditions it defines the water vapor mixing ratio as we11. Thus, two saturated air masses at different temperatures are completely defined by their wet bulb temperatures and the properties of their mixture are defined as we 11 .

In practice, the enthalpy (EN) of the mixture is determined and this in turn specifies the wet bulb temperature. The wet bulb temperature $\left(T_{W}\right)$ defines the water vapor mixing ratio of the mixture which is subtracted from the mixing ratio determined as the mean of the mixing ratios of the two air masses to give the liquid water content (LWC).

An example is provided in Tables 4 and 5 of mixing a saturated plume at $34^{\circ} \mathrm{C}$ with ambient air saturated at $10^{\circ} \mathrm{C}$.

TABLE 4. Conditions for Example Condensed Water Calculation

$\begin{array}{lcr} & \text { Ambient } & \text { Plume } \\ \text { Wet bulb temperature } T_{W}, C & 10 & 34 \\ \text { Enthalpy EN, cal } / \mathrm{kg} & 6939 & 27507 \\ \text { Mixing ratio MR, gm/kg } & 7.76 & 35.13\end{array}$


.

.

. 
TABLE 5. Condensed Water Calculations for Example Cooling Tower Plume

\begin{tabular}{|c|c|c|c|c|c|c|c|}
\hline $\begin{array}{l}\text { Ratio of ambient } \\
\text { to plume masses }\end{array}$ & $\begin{array}{l}E N \operatorname{mix}_{x} \\
(\mathrm{cal} / \mathrm{kg})\end{array}$ & $\begin{array}{l}\text { Tw } \\
(\mathrm{C}) \\
\end{array}$ & $\begin{array}{c}M R \\
(g m / k g)\end{array}$ & $\begin{array}{l}M R \operatorname{mix} \\
(\mathrm{gm} / \mathrm{kg})\end{array}$ & $\begin{array}{c}\triangle M R \\
(\mathrm{gm} / \mathrm{kg}) \\
\end{array}$ & $\begin{array}{c}\mathrm{LWC} \\
\left(\mathrm{gm} / \mathrm{m}^{3}\right) \\
\end{array}$ & $\mathrm{CW}^{\mathrm{a}}$ \\
\hline 1 & 17223 & 24.55 & 19.89 & 21.44 & 1.55 & 1.83 & 3.10 \\
\hline 2 & 13795 & 20.55 & 15.49 & 16.88 & 1.39 & 1.67 & 4.17 \\
\hline 5 & 10367 & 15.75 & 11.38 & 12.32 & 0.94 & 1.15 & 5.64 \\
\hline 10 & 8809 & 13.30 & 9.69 & 10.25 & 0.56 & 0.69 & 6.16 \\
\hline 15 & 8224 & 12.30 & 9.07 & 9.47 & 0.40 & 0.49 & 6.40 \\
\hline 20 & 7918 & 11.80 & 8.77 & 9.06 & 0.29 & 0.36 & 6.09 \\
\hline 30 & 7602 & 11.25 & 8.45 & 8.64 & 0.19 & 0.24 & 5.89 \\
\hline 40 & 7441 & 10.90 & 8.25 & 8.43 & 0.18 & 0.22 & 7.38 \\
\hline 50 & 7342 & 10.72 & 8.15 & 8.30 & 0.75 & 0.19 & 7.65 \\
\hline 60 & 7276 & 10.60 & 8.09 & 8.21 & 0.12 & 0.15 & 7.32 \\
\hline 80 & 7193 & 10.45 & 8.01 & 8.10 & 0.09 & 0.11 & 7.29 \\
\hline 100 & 7143 & 10.35 & 7.95 & 8.03 & 0.08 & 0.10 & 8.08 \\
\hline 200 & 7041 & 10.20 & 7.87 & 7.90 & 0.03 & 0.04 & 6.03 \\
\hline
\end{tabular}

${ }^{\mathrm{a}}$ Condensed water in the mixture, grams per each $\mathrm{kg}$ of effluent 

The product of $\triangle M R$ and the total mass of the mixture containing $1 \mathrm{~kg}$ of the effluent yields the total liquid water $(\mathrm{CW})$ in the mixture for each $\mathrm{kg}$ of effluent (last column of Table 5 ).

Except in the early stages of dilution when temperatures are quite elevated, the amount of condensed water is fairly constant. For a typical effluent flow of $2.5 \times 10^{4} \mathrm{~kg} / \mathrm{sec}$, the condensed water flow would be approximately $1.7 \times 10^{5} \mathrm{gm} / \mathrm{sec}$ under the assumed conditions.

This is the condition which is of maximum interest in regard to the washout of cloud droplets by natural precipitation. 



\section{APPENDIX II}

\section{PLUME DROPLET SIZE DISTRIBUTION USED IN SCAVENGING ESTIMATES}

A series of plume traverse measurements were made at Trojan power plant in northwest Oregon in May 1976. The results of these and others are described in more detail elsewhere; ${ }^{9}$ for purposes of the scavenging calculations, a spectrum measured on May 13 was chosen. On one traverse, where the plume width was about $250 \mathrm{~m}$, the mean liquid water content (LWC) was $0.15 \mathrm{~g} / \mathrm{m}^{3}$. The droplet size spectrum, measured with a laser spectrometer, at the apparent center of the plume $\left(L W C=0.22 \mathrm{~g} / \mathrm{m}^{3}\right.$ ) is shown in Table 6.

Both the number and mass (LWC) distributions appear nearly Gaussian, though slightly offset in size. Because of the general characteristics of the measuring instrument, there may be a tendency for a small deficiency in the numbers reported in the first two intervals (0.5-2.5 $\mu$ m radius); thus, the actual distribution may be more lognormal in character. However, this correction should not significantly affect the mass mean droplet radius $(\sim 5 \mu \mathrm{m})$.

The near-Gaussian nature of the droplet size distribution in this case simplifies the plume droplet size input to scavenging calculations. Such calculations for non-Gaussian, or, in general, polydisperse aerosol spectra, require integration over the aerosol spectrum, or at least, a strong knowledge of the "scavenging-effect" mean radius. These are related to the moments of the distribution, or mean length radius, mean area radius, etc. In the case of the inertial scavenging scheme used for estimation here, the area mean is of importance. However, approximation of the spectrum as a Guassian one, where all the mean radii are the same, allows the specification of a single parameter to describe the scavenging characteristics of the spectrum. We have chosen in this case $5 \mu \mathrm{m}$, or the approximate mass mean radius. 

TABLE 6. Plume Droplet Spectrum Used in Scavenging Estimates. Measured at Trojan Power Plant on May 13, 1976

Radius interval
$(\mu \mathrm{m})$

$0.5-1.5$

$1.5-2.5$

$2.5-3.5$

$3.5-4.5$

$4.5-5.5$

$5.5-6.5$

$6.5-7.5$

$7.5-8.5$

$8.5-9.5$

$9.5-10.5$

$10.5-11.5$

$11.5-12.5$

$12.5-13.5$

$13.5-14.5$

$14.5-15.5$
Fraction of total in interval (\%)

Number

3

11

25

30

20

7

3

1

0

0

0

0

0

0

0

\section{Mass}

0

1

9

24

30

19

11

6

0

0

0

0

0

0

0 


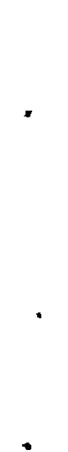




\section{DISTRIBUTION}

No. of

Copies

\section{OFFSITE}

1 ERDA Chicago Patent Group

$\overline{9800}$ South Cass Avenue

Argonne, IL 60439

A. A. Churm

8 Energy Research and Development Administration Division of Nuclear Research \& Application Advanced Concepts Evaluation Branch Washington, DC 20545

T. Beresovski (5)

W. F. Savage (3)

5 Energy Research and Development Administration Division of Biomedical and Environmental Research Washington, DC 20545
D. S. Ballentine
H. Moses (3)
D. L. Slade

3 Energy Research and Development Administration Division of Nuclear Research \& Applications Washington, DC 20545
A. M. Rubin
G. L. Sherwood
S. Strauch

1 Energy Research and Development Administration Office of Assistant General Counsel for Patents Washington, DC 20545

1 Energy Research and Development Administration Division of Reactor Development \& Demonstration Washington, DC 20545

E. S. Beckjord

\section{ERDA Technical Information Center}




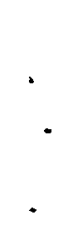


No. of

Copies

6 Argonne National Laboratory

9700 South Cass Avenue

Argonne, IL 60439

J. Carson

B. B. Hicks (3)

A. J. Policastro

M. L. Wesely

1 R. W. Beck \& Associates

400 Prudential Plaza

Denver, CO 80202

J. P. Rossie

1 Chalk Point Cooling Tower Project

c/o Bureau of Air \& Quality \& Noise Control

$0^{\prime}$ Connor Bldg.

201 West Preston Street

Baltimore, MD 21201

R. S. Nietubicz

1 Clemson University

Environmental Systems Engineering

Clemson, SC 29631

T. J. Overcamp

1 Colorado State University

Department of Atmospheric Science

Fort Collins, CO 80523

W. R. Cotton

1 Ecodyne Cooling Products Company Santa Rosa, CA 95403

J. K. Swindt

4 Electric Power Research Institute 3412 Hillview Avenue

P. 0. Box 10412

Palo Alto, CA 94304

C. Hakkarinen

J. S. Maulbetsch

R. Perhac

S. C. Schurr 


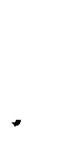


No. of

Copies

2 Environmental Protection Agency

National Environmental Research Center

Research Triangle Park, NC 27711

W. N. Snyder

B. J. Steigerwald

3 Environmental Protection Agency

Pacific Northwest Water Laboratory

200 S. W. 35th Street

Corvallis, OR 97330

F. H. Rainwater

M. Shirazi

L. Winiarski

1 Environmental Protection Agency

Region IX

100 California Street

San Francisco, CA 94111

P. Defalco, Jr.

1 Environmental Protection Agency Region $X$

1200 Sixth Avenue

Seattle, WA 98101

c. V. Smith, Jr.

1 Environmental Systems Corporation P. 0. Box 2525

Knoxville, TN 37901

G. Schrecker

1 Federal Power Commission

Bureau of Power

Washington, DC 20426

A. Gakner

1 Flow Research, Inc.

Suite 72

1819 Central Avenue

Kent, WA 98031

$Y-H$. POO 

No. of

Copies

1 GEA Airexchangers; Inc.

46 Worthington Drive

Maryland Heights, MD 63043

B. Davis

1 Heat Tränsfer Research, Inc.

$1000 \mathrm{~S}$. Fremont Avenue

Alhambra, CA 91802

J. E. Taboric

1 Hudson Products 6855 Horwin Drive Houston, TX 77036

E. C. Smith

1 Illinois State Water Survey Box 232

Urbana, IL 61801

J. L. Voge 1

1 Lawrence Livermore Laboratory

P. 0. Box 808

Livermore, CA 94550

M. C. McCracken, L- 142

1 Martin-Marietta Corporation Baltimore, MD 21240

J. C. Weit

1 Meteorology Research Inc.

P. 0. Box 637

Altadena, CA 91001

$P$. Harrison

1 G. E. McVehi1

P. O. Box 4480

Boulder, CO 80302

3 National Center for Atmospheric Research Boulder, CO 80302

J. W. Deardorff

D. Lenschow

$P$. Squires 


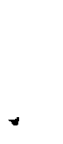


No. of

Copies

4 National Oceanic and Atmospheric Administration

Atmospheric Turbulence \& Diffusion Laboratory

P. 0. Box E

Oak Ridge, TN 37830

F. A. Gifford (2)

S. R. Hanna

C. J. Nappo

1 National Science Foundation

1800 G Street, NW

Washington, DC 20550

R. A. Dirks

1 Northwestern University

Dept. of Mechanical Engineering \& Astronautical Sciences

Evanston, IL 60201

A. L. Kistler

1 Nuclear Regulatory Commission Washington, DC 20555

R. L. Ballard

2 Nuclear Regulatory Commission

Office of Nuclear Reactor Regulation Washington, DC 20555

H. R. Denton

J. E. Fairobent

1 Nuclear Regulatory Commission

Office of Nuclear Regulatory Research Washington, DC 20545

R. F. Abbey, Jr.

2 Nuclear Regulatory Commission

Office of Special Studies

Washington, DC 20545

M. L. Ernst

R. T. Jaske

1 Nuclear Regulatory Commission

Office of Standards Development

Washington, DC 20555

R. Kornasiewicz 

No. of

Copies

8 Oak Ridge National Laboratory

P. 0. Box X

Oak Ridge, TN 37830

C. C. Coutant

D. M. Eissenberg (3)

W. H. Hoffman (2)

H. A. MCLain

T. H. Tow

4 Oak Ridge National Laboratory P. 0. BoX Y

Oak Ridge, TN 37830

N. C. J. Chen

R. L. Miller

A. A. N. Patrinos

I. Spiewak

1 Oregon State University

Atmospheric Sciences Department Corvallis, OR 97331

M. A. Wolf

3 Pennsylvania State University Department of Meteorology University Park, PA 16802

J. Lee

J. M. Norman

D. W. Thomson

1 Power Generating Cooling Systems

4714 52nd Street South Seattle, WA 98118

A. C. Smith

2 Rand Corporation

1700 Main Street

Santa Monico, CA 90406

L. R. Koenig

F. W. Murray

1 Research Cottre11

Hamon Cooling Tower Division

P. 0. Box 750

Bound Brook, NJ 08805

G. E. Collins 


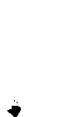


No. of

Copies

1 Savannah River Laboratory

Environmental Transport Division

Aiken, SC 29801

T. Crawford

1 Smith-Singer Meteorologists, Inc.

134 Broadway

Amityville, NY 11701

M. L. Kramer

1 South Dakota School of Mines \& Technology

Institute of Atmospheric Sciences

Rapid City, SD 57701

H. D. Orville

1 Southern Company Services, Inc.

P. 0. Box 2625

Birmingham, AL 35202

C. H. Goodman

2 Stone \& Webster Engineering Corporation 225 Franklin Street

Boston, MA 02107

Y. C. Chen

D. H. Guild

1 Texas A\&M University

Dept. of Mechanical Engineering

College Station, TX 77840

S. A. Anderson

1 Tennessee Valley Authority

Air Quality Branch

River Oaks Building

Muscle Shoals, AL 35660

J. H. Coleman

1 University of Chicago

Chicago, IL 60637

R. R. Braham, Jr. 
.

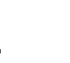


No. of

Copies

1 University of Iowa

Iowa City, IA 52240

J. F. Kennedy

2 University of Michigan

Dept. of Atmospheric \& Oceanic Science

Ann Arbor, MI 48109

A. N. Dingle

E. Ryzner

1 University of North Dakota

Grand Forks, ND 48202

P. J. Brady

1 University of Washington

Dept. of Atmospheric Sciences

Seattle, WA 98195

P. Hobbs

1 University of Waterloo

Dept. of Mechanical Engineering

Waterloo, Ontario,

CANADA

P. STawson

1 University of Wyoming Laramie, WY 82070

A. H. Auer, Jr.

1 Washington State Department of Ecology OTymipia, WA 98504

J. Biggs, Director

1 West Associates

Sierra Pacific Power Company

100 E. Moana Lane

Reno, VN 89510

G. H. Soule 
No. of

Copies

ONSITE

2 ERDA Richland Operations Office

H. E. Ransom

M. W. Tiernan

1 Washington Public Power Supply System 300 George Washington Way

Richland, WA 99352

D. D. Tillson

1 Westinghouse Hanford Company

J. Fletcher

41 Battelle-Northwest

S. M. Brown

D. W. Cearlock

M. T. Dana (15)

D. W. Dragnich

R. L. Drake

C. E. Elderkin

R. K. Hadlock (3)

H. Harty

B. M. Johnson (2)

L. D. Kannberg

N. S. Laulainen

D. E. Olesen

Y. Onishi

M. M. Orgill

J. V. Ramsdell

C. [. Simpson

J. M. Thorp

D. S. Trent

Technical Information (5)

Technical Publications 
